\title{
DvB's PREFACE
}

SIR JOHN BeAZLey died in 1970, and two years later the University of California Press expressed an interest in bringing out a new edition of The Development of Attic BlackFigure. The trustees of the literary estate of Sir John Beazley, Professors Bernard Ashmole and Martin Robertson, consented to the suggestion that the undersigned undertake the revisions, made necessary by the decades that had elapsed after the printing of the first edition.

This edition limits itself to bringing up to date the bibliography contained in the notes, the correction to misprints, and to those (very few) changes of factual statement in the text, chiefly pertaining to the count of signatures or numbers of given shapes or subjects that were necessitated by new material. Beazley's own "Addenda to the Notes" and his corrections in the second printing of the book (1964) have been incorporated, and a few new notes, recognizable by bis numbers, have been added where needed. No attempt has been made to eliminate minor inconsistencies in transliterations, capitalizations or italicising, unless they affect the meaning or understanding of the text. We are grateful to Joan R. Mertens who has helped in the final proofreading.

Since Beazley had been particularly pained by the physical appearance of the plates in the first and second editions, the illustrative part of the book has been redone, omitting the contouring to which Beazley had objected all his life, substituting better prints, and adding many more plates. For these additional plates we thank all the collectors and museums whose vases are illustrated in this new edition. 
